\title{
Performatividades de Gênero em Unidades Prisionais Femininas do Rio de Janeiro
}

\author{
Luisa Bertrami D’Angelo ${ }^{1}$ \\ ${ }^{1}$ Universidade do Estado do Rio de Janeiro, RJ, Brasil. \\ Vanessa de Andrade da Costa ${ }^{2}$ \\ ${ }^{2}$ Universidade Federal do Rio de Janeiro, RJ, Brasil. \\ Bárbara Silva da Rocha ${ }^{1}$ \\ ${ }^{1}$ Universidade do Estado do Rio de Janeiro, RJ, Brasil. \\ Vanessa Pereira de Lima \\ ${ }^{1}$ Universidade do Estado do Rio de Janeiro, RJ, Brasil. \\ Jimena de Garay Hernández ${ }^{1}$ \\ ${ }^{1}$ Universidade do Estado do Rio de Janeiro, RJ, Brasil. \\ Gabriela Salomão Alves Pinho ${ }^{3}$ \\ ${ }^{3}$ Instituto Federal do Rio de Janeiro, RJ, Brasil. \\ Anna Paula Uziel ${ }^{1}$ \\ ${ }^{1}$ Universidade do Estado do Rio de Janeiro, RJ, Brasil.
}

Resumo: O Brasil vive hoje um superencarceramento e, em seu bojo, tem especial destaque o aumento da população carcerária nas unidades femininas. Este artigo tem como objetivo pensar, a partir de algumas linhas que conectam três pesquisas realizadas entre 2009 e 2017, no Rio de Janeiro, como se des/re/criam performatividades de gênero no contexto de unidades prisionais femininas. Para tal, convidamos algumas personagens, conjugando interlocutoras que habitaram os campos de pesquisa, para ingressarmos em uma Cartografia, perspectiva que costura um posicionamento ético, político e metodológico. Através de catuques e cartas como dispositivos de escrita, essas personagens se narram nas forças que compõem a trama de relações de poder, afeto e erotismo nas experiências de restrição e privação de liberdade. A partir disso, discutiremos como performatividades de gênero, conformando e transbordando categorias, compõem a paisagem prisional, habitada por intensidades, jogos, disputas e negociações, constituindo linhas que produzem variados arranjos de gênero e sexualidade.

Palavras-chave: Performatividades, Prisão Feminina, Gênero, Sexualidade, Cartografia.

\section{Gender Performativities in Female Prison Units in Rio de Janeiro}

\begin{abstract}
Brazil deals today with a process of mass incarceration that has as one ofits developments a stunning increase of the female prison population. This article's objective is to think about gender performativities in female prisons and how they are done, undone and remade. For that, we will analyze three researches that took place in Rio de Janeiro from 2009 to 2017. In order to do so, we created three fictional characters conjugating elements of real people that we interviewed and that guide a cartography of female prisons. We use Cartography as a method and aesthetic/ politic positioning and as a starting point. Through notes and scraps that are frequently used by those who are incarcerated, these characters will show themselves and the forces that connect the network of power relations, affection and eroticism in the experiences of restriction and deprivation of liberty. With and through them, we will discuss how gender performativities and identity categories comprise the prison landscape, inhabited by intensities, games, disputes and negotiations, constituting lines that produce varied arrangements of gender and sexuality.
\end{abstract}

Keywords: Performativities, Female Prison, Gender, Sexuality, Cartography. 


\title{
Performatividades de Género en Unidades Penitenciarias femeninas de Río de Janeiro
}

\begin{abstract}
Resumen: Brasil vive hoy un superencarcelamiento y, en su conjunto, tiene especial destaque el aumento de la población carcelaria en las unidades femeninas. Este artículo tiene como objetivo pensar, a partir de algunas líneas que conectan tres investigaciones realizadas del 2009 al 2017, en Río de Janeiro, cómo se des/re/crean performatividades de género en el contexto de las prisiones femeninas. Para esto, invitamos a algunos personajes, conjugando interlocutoras que habitaron los campos de investigación, para ingresar a una Cartografía, perspectiva que teje un posicionamiento ético, político y metodológico. A través de catuques y cartas como dispositivos de escritura, esos personajes se narran en las fuerzas que componen la trama de relaciones de poder, afecto y erotismo en las experiencias de restricción y privación de libertad. A partir de eso, discutiremos cómo performatividades de género, conformando y transbordando categorías, componen el paisaje penitenciario, habitado por intensidades, juegos, disputas y negociaciones, constituyendo líneas que producen variados arreglos de género y sexualidad.
\end{abstract}

Palabras clave: Performatividades, Prisión Femenina, Género, Sexualidad, Cartografía.

\section{Introdução}

As prisões femininas no Brasil (se) apresentam, cada vez mais, resultados da trama que envolve a chamada "guerra às drogas" e o superencarceramento, demonstrando que não há fronteiras para a insaciável criminalização dos conflitos sociais e das estratégias de sobrevivência da pobreza e da população desempregada (Batista, 2010), constituindo determinados corpos como os principais alvos desses processos. Dados do Levantamento Nacional de Informações Penitenciárias - Infopen Mulheres (2018) mostram que, em junho de 2016, as prisões femininas (e mistas) $^{1}$ (con)tinham 42.355 pessoas designadas como mulheres ao nascimento ${ }^{2}$. Neste amplo contingente, são múltiplos as possibilidades e os entrelaçamentos entre performatividades de gênero, sexualidades, desejos, prazeres e violências, sempre agenciados/ produzidos por uma série de atravessamentos, disputas, poderes e negociações.

Falar sobre presídios femininos não significa pressupor uma unidade no que diz respeito às experiências de gênero, bem como àquilo que se entende por "feminino" ou "masculino". Falar sobre prisões femininas, assim, não é falar sobre "a mulher presa", ou sequer sobre mulheres presas, mas sim sobre pessoas privadas ou restritas de liberdade em unidades femininas - pessoas estas que vivem, narram e apresentam múltiplas expressões e performatividades de gênero.

Se o gênero é performativo, o que designa homens e mulheres é a própria performatividade, de modo que o binômio homem/mulher não dá conta dos agenciamentos e negociações que produzem performatividades de gênero. O corpo, bem como o gênero, é performativo, múltiplo, de modo que o próprio corpo coloca em análise o modelo hegemônico de gênero e sexualidade.

Este texto pretende costurar experiências de campo de três pesquisas realizadas em unidades prisionais femininas no Rio de Janeiro entre 2009 e 2017. Esta costura se dará através de personagens que habitaram estes campos e que, a partir de suas narrativas e da noção de "performatividades de gênero" (Butler, 2010), indicarão pistas a respeito dos modos como, nas prisões femininas, gênero e sexualidade são produzidos a partir e através de repertórios que constituem contornos, aberturas e fechamentos nos corpos, nas instituições, nas relações de erotismo, poder, afeto e violência.

As performatividades de gênero no contexto das prisões femininas falam sobre ser mulher, sapatão,

\footnotetext{
${ }^{1}$ De acordo com dados do InfoPen Mulheres, "há o indicativo de 238 estabelecimentos mistos (17\%) e 103 estabelecimentos femininos (7\%), significando, assim, que a maior parte das mulheres estão em estruturas mistas".

${ }^{2}$ O InfoPen Mulheres utiliza o termo "mulheres" para se referir a estas pessoas; no entanto, optamos por abrir mão desta categoria nas análises do presente texto, como será melhor explicado posteriormente.
} 
mulherzinha, entendida, bolinha-vai-bolinha-vem, sapatão de rua, sapatão de berço ${ }^{3}$ e outras categorias - máscaras que deixam passar diferentes intensidades e que tomam forma na medida em que fazem sentido para o desejo, produzindo relações de afeto e de poder e indicando diferentes modos de habitar a prisão.

Neste texto, discutiremos como performatividades de gênero compõem a paisagem que permeamos como cartógrafas, explorando unidades prisionais femininas nestas pesquisas. Instigadas pelas performatividades de gênero que habitam esses territórios, convidamos a um passeio em meio a intensidades, jogos, disputas e negociações pelas linhas que arranjam gênero e sexualidade nas prisões femininas.

\section{Metodologia}

É do encontro entre pesquisas distintas, mas afinadas teórica e metodologicamente, que nasce este trabalho. Partindo de três pesquisas, portanto três campos em momentos distintos, em especial no que se refere às discussões de direitos sexuais e reprodutivos e à gramática da violência urbana e sua relação com a criminalidade e a criminalização, pensar a prisão feminina, a partir das linhas que unem estes campos, no decorrer de oito anos de trabalho, potencializa a discussão sobre a processualidade da pesquisa, na medida em que aciona tempos e espaços diversos a partir de suas tensões, similitudes e diferenças.

Pensar o método a partir de um paradigma ético / estético/político (Rolnik, 1993) possibilita uma abertura à experiência e, assim, faz da pesquisa de campo uma tentativa de acompanhar processos, mais do que produzir verdades estáveis e absolutas. Neste caso, experimentar faz parte da produção de dados não preestabelecidos, tampouco fixados, que nos permitiram construir as pesquisas de forma caleidoscópica, isto é, um processo de construção e desconstrução, sendo a experiência com as interlocutoras o principal objetivo. Neste sentido, as escolhas metodológicas das pesquisas às quais este artigo se refere podem não ser exatamente as mesmas, mas compartilham da percepção de que o campo só pode ser vivido/experimentado a partir de sua processualidade. Assim, todas buscaram, por meio de diferentes dispositivos e diálogos, mapear as intensidades e as composições e decomposições das relações e das linhas de fuga presentes nas porosidades da prisão.
O que une as pesquisas, portanto, é uma certa inclinação frente ao campo que procura encontrar as brechas, os entres, aquilo que deixa ver e falar as forças e tensões que constituem sujeitos, experiências e saberes. Por conseguinte, compartilham uma ética, uma postura que pretende deixar-se aberta à surpresa, ao inesperado. Ao mesmo tempo, se há uma postura ético/estético/política que as une, dando pistas a respeito de como as escolhas metodológicas constituem-se como parte de um campo de pesquisa, as diferenças que elas apresentam dão elementos para pensar de que forma pesquisas inseridas em tempos e contextos distintos lançam mão de ferramentas distintas para conhecer um campo que, ainda que seja o mesmo, constitui-se diferente por estar em constante transformação.

Pesquisar a partir da linguagem do encontro, que procura pensar as relações pelos afetos, sendo o encontro um processo de afetar e ser afetado (Salles, 2014), é buscar caminhos para potencializar que o processo de habitar o campo produza esses encontros, o que às vezes é possível, mas nem sempre acontece facilmente. Pensar na construção de um pesquisarCOM (Bicalho, Rossotti,\& Reishoffer, 2016) em instituições prisionais esbarra com forças e intensidades que muitas vezes são como barreiras para que encontros se efetivem.

Da mesma forma, pensar ética em pesquisa nestes contextos implica levar em consideração as particularidades apresentadas pelo campo, o que exige a construção de estratégias e posicionamentos que deem conta da complexa trama de disputas, afetos e poderes que atravessam a pesquisa. Como pensar um pesquisarCOM, a construção coletiva de conhecimento a partir de um plano comum (Kastrup,\& Passos, 2015) quando nos deparamos com pessoas que, privadas ou restritas de liberdade, veem-se ali, frente a pesquisadoras, sem poder de fato decidir se querem ou não estar ali? De que maneiras criar estratégias frente às negociações que se fazem exigir junto à instituição?

Leite (2014), narrando sua empreitada na construção de uma cartografia a/na prisão, aponta que as "relações de poder/saber predominantemente enrijecidas e verticais tendem a colocar a comunicação a serviço do controle" (p. 799), cristalizando modos de subjetivação. A autora segue dizendo que "o cárcere é formado principalmente por linhas duras, que cortam

\footnotetext{
${ }^{3}$ Expressões próprias ao universo prisional, categorias autoidentificadas, utilizadas e explicitadas ao longo deste texto.
} 
dicotomizando [...] Contudo, invisibilizada pelas grades, a vida ainda (r)existe e desafia a ser cartografada" (Leite, 2014, p. 810).

Nesse contexto, encontramos um fio condutor a partir do "ethos cartográfico" (Tedesco, Sade \& Caliman, 2013). Sentimos necessidade de repensar conceitos e temas que emergiram com e no campo, a partir da análise de nossas implicações (Coimbra, \& Nascimento, 2008), pondo em pauta as inúmeras interpelações políticas do nosso lugar enquanto pesquisadoras naqueles espaços.

A primeira pesquisa, realizada entre 2009 e 2011, teve como objetivo pesquisar os sentidos de maternidade para as mulheres do sistema prisional do Rio de Janeiro que tinham parido nos dois anos anteriores ao início do campo e tivessem vivenciado a maternidade no cárcere. Foram entrevistadas 37 mulheres em diferentes momentos: algumas ainda estavam com seus e suas bebês na Unidade Materno Infantil (UMI), outras haviam voltado para suas unidades de origem e outras, ainda, já se encontravam em liberdade condicional.

Na segunda pesquisa, realizada entre 2013 e 2014, a ideia foi entrevistar pessoas presas em unidades femininas que, ao longo da vida, tivessem se relacionado sexual e/ou afetivamente com mulheres. Foram feitas 37 entrevistas abertas e individuais, centradas na história de vida dessas pessoas. Na terceira pesquisa, por fim, realizada entre 2015 e 2017, foram realizadas 11 entrevistas, com o objetivo de discutir e acompanhar processos de produção de feminilidades em contextos de privação de liberdade voltados para mulheres.

Diante da impossibilidade de gravar as entrevistas no ambiente prisional, nas três pesquisas, o método de registro foi a elaboração de diários de campo e anotações por parte das entrevistadoras, que depois compunham o relato/escritura com suas diferentes e semelhantes escutas. A partir dessas anotações e das suas análises, propomos aqui traçar um plano comum entre as pesquisas, a começar pela construção de personagens fictícias que, conjugando em si mesmas elementos e falas de inúmeras pessoas que participaram das três pesquisas, dão importantes pistas a respeito dos modos como pessoas presas em unidades femininas produzem, mantêm e desmancham seu gênero e sobre os atravessamentos entre gênero, sexualidade e prisão.

Usamos como dispositivos deste texto dispositivos que são acionados nas prisões femininas, os catuques ${ }^{4}$ e cartas. Nossas personagens irão narrar, através desses dispositivos comunicacionais, como enredam tramas afetivas no cotidiano prisional e de que maneira acionam determinadas performatividades de gênero tanto como forma de negociação/estratégia de, por exemplo, proteção e/ou afirmação, quanto como modo de narrarem a si mesmas e as pessoas que com elas convivem na prisão.

\section{Resultados e discussão}

Especialmente ao longo da segunda pesquisa, que abordou relações afetivas e/ou sexuais na prisão, mas não somente nela, uma questão inquietante foi o uso ou não-uso dos termos "mulher", "lésbica" e "relação homoafetiva" ou "homossexual" - que, ainda que constassem no projeto original, foram confrontados com o que o campo apresentava. O que as prisões femininas diziam era que, ali, não estavam apenas mulheres, elas não eram apenas heterossexuais ou lésbicas e as relações afetivo-sexuais não se davam a partir da noção "homossexualidade".

Desta forma, era possível encontrar outras identidades de gênero para além de "mulher" nas falas de pessoas que se relacionam com mulheres, sejam elas cis ou trans ${ }^{5}$, e que não consideram suas relações enquanto homoafetivas nem homossexuais. Assim, "pessoas que em algum momento da vida intra ou extramuros já tiveram, ou têm, alguma relação sexual e/ou afetiva com mulheres" parecia contemplar melhor o campo ${ }^{6}$.

É importante ressaltar que as pesquisas foram produzidas em momentos distintos no que tange às legislações e ao modo como o poder judiciário lida com os atravessamentos entre gênero e prisão. À época

\footnotetext{
${ }^{4}$ Catuque é o nome dado aos bilhetes usados nos presídios femininos para comunicação entre as(os) presas(os) e com a instituição.

${ }^{5}$ Uma pessoa cis se identifica com o sexo e gênero designados ao nascimento, enquanto uma pessoa trans se identifica com outro sexo e gênero designados ao nascimento.

${ }^{6}$ As mudanças e avanços nos estudos de gênero e na militância LGBT, hoje, permitem pensar, inclusive, que as pessoas com as quais estas pessoas se relacionam/se relacionaram também podem não estar contempladas na categoria “mulher". No entanto, à época, isso não apareceu como questão.

${ }^{7}$ O cenário foi modificado a partir da Resolução no 558 de 29 de maio de 2015, que "estabelece diretrizes e normativas para o tratamento da população LGBT no Sistema Penitenciário do Estado do Rio de Janeiro".
} 
das primeiras pesquisas, ainda não se reconhecia, no Rio de Janeiro, a orientação sexual e a identidade de gênero dos sujeitos ingressantes no sistema penal ${ }^{7}$, de modo que estas questões eram tratadas diferentemente da maneira como o são hoje. Para além do reconhecimento ou não do Estado destas identidades e orientações, a forma como se lida com elas é pautado por uma série de negociações, disputas e afetos cotidianos. Se noções como "mulher" e "mulher presa” pouco contribuem para identificar e acompanhar as forças que produzem gênero na prisão, tampouco "lésbica", "gay", "trans" ou "travesti" pareceram dar conta daquilo que emerge neste campo.

\section{Rubi, Sandra e Enrique entre performatividades, disputas e afetos}

Nas primeiras cartas de Rubi, Sandra e Enrique, nossas personagens, vemos algumas pistas sobre as tramas que enredam gênero, sexualidade, afetos, disputas e prisão.

Aqui tem muito sapatão. Têm umas que acham que são homem mesmo. Eu acho muito estranho, uma mulher ficar coçando pano como se tivesse alguma coisa ali. Muitos, quando chegam na cadeia, raspam a cabeça, colocam uma roupa masculina e dizem que são sapatões de rua, virgens, mas se puxar suas fichas vão ver que elas deram pra caramba, têm não sei quantos filhos. Tem muita mulher que chega aqui e vira sapatão e, quando sai lá fora, está sentando. Há pouco tempo, um sapatão saiu da cadeia e voltou de barriga. Têm outros que, no dia da visita, vão de roupa justinha. Eu sou lésbica, sou mulheríssima, mas gosto de mulher. Minha mulher também é feminina, faz sobrancelhas, pinta a unha, se cuida - nem tem cara de lésbica. Mas não é fácil. Aqui, tem uma pressão grande pra ser ou uma coisa ou outra: ou é sapatão, ou é mulher. Quando eu sair, não vou ficar mais com mulher. Eu gosto de homem. Mulher, só aqui. Lá fora, não me imagino com uma mulher de cabeça raspada e roupa de homem. (Rubi)

Eu sou sapatão. Gosto de manter meus cabelos curtos e usar roupas largas. Lá fora, antes de ser presa, já havia me relacionado com homens e mulheres, mas mesmo antes, eu já sabia que isso era errado. O homossexualismo é errado na lei de Deus, mas esse foi o caminho que eu escolhi. Algumas pessoas aqui viram sapatão e começam a usar nome de homem, um vulgo, mas eu preferi manter meu nome de mulher. Ainda assim, sou respeitada como todo sapatão aqui dentro. Tenho uma mulher aqui. Estamos juntas há dois anos. Nosso dia a dia é normal, igual ao de todo casal, só que presas... estar com ela é muito bom, porque também ajuda a lidar com a saudade do meu filho. (Sandra)

Na prisão, namorei sete vezes, mas todas elas já estão na rua. Sou até conhecida como sapatão do alvará. Eu sou de me entregar muito quando me relaciono e se ela não tivesse saído, estaria com a primeira até hoje. Tem muito sapatão promíscuo, eles só querem sexo. Mesmo quando estão com alguém, saem comendo tudo que é mulher, saem fazendo a limpa. Mesmo que eu seja masculinizada, odeio que me chamem de ele, mas precisei aceitar porque estou presa. Gisele e as crianças estranharam minha aparência masculina e, então tive que explicar o motivo de estar me vestindo dessa forma. Não sou sapatão, é muito ruim ter que viver uma coisa que eu não sou, já basta tá aqui presa sendo inocente. Aqui na cadeia é assim: lésbica aqui dentro gosta de homem e de mulher, mas duas lésbicas juntas são malvistas e sofrem discriminação. Já que eu não gosto de homem, tive que me tornar sapatão, mesmo odiando, mesmo não me sentindo eu de verdade. Lá fora, sou feminina. Aqui na cadeia é muito esquisito esse lance de pederastia. É por isso que tenho que fingir que sou sapatão, porque eu gosto de mulher feminina. Aqui dentro, eu uso roupas masculinas, não me deixo ser tocada e faço tudo que um sapatão deve fazer. Na rua, eu não me vestia como homem e deixava que me tocassem durante o sexo, com minha esposa fazia de tudo. Fui obrigada a assumir esse lugar de sapatão por medo. Quem é entendida, aqui dentro, os sapatão querem bater. Eu sou entendida. Lésbica é a maneira como as pessoas falam, mas não sou nem lésbica e nem sapatão, sou entendida. Como sapatão, não posso deixar que me toquem na hora do sexo. Mas, com a minha companheira, às vezes eu deixo - desde que ela não conte pra ninguém. (Enrique) 
Padovani (2017) aponta que o termo "encarceramento feminino" opera genericidades que não dão conta de contemplar a multiplicidade de experiências que tomam corpo nas prisões femininas; tampouco a ideia de especificidade da "mulher presa" leva em conta que "mulher" não é uma categoria facilmente delimitável, especialmente neste contexto, e que partir de diferenças biológicas para pensar estas "especificidades", que geralmente aparecem em termos de "gravidez" e/ou "necessidade de absorventes”, produz marginalizações e apagamentos de experiências de gênero outras que não de um feminino default.

Nesse sentido, Rubi, Sandra e Enrique evidenciam que "mulheres presas", ou mesmo "mulheres", são categorias insuficientes e excludentes que não são capazes de falar sobre as experiências de gênero, relações sexuais, as tramas de afeto e as disputas que se desenrolam na prisão feminina. Do mesmo modo, apontam que as categorias "masculino" e "feminino" podem ter suas fronteiras borradas, na medida em que ser mulher não descarta ter um nome masculino, assim como ser sapatão não envolve os mesmos desejos nem as mesmas performances sexuais.

Enquanto categorias que nomeiam experiências e processos de subjetivação, tais termos não estão apartados das forças políticas que os (re)produzem. Rubin (1975) chama a atenção para o que há de político no gênero e em como ele aciona/produz disputas, negociações, poderes, saberes e interesses. O sistema sexo/gênero produz determinados repertórios de gênero a partir da delimitação do que seria "masculino", "feminino", "homem", "mulher", de modo a manter e reproduzir a heteronormatividade (Butler, 2010; Rich, 2010), "entendida como a imposição da norma heterossexual como única forma válida de se relacionar" (de Garay, 2018, p. 179).

A prisão, ao mesmo tempo em que, através do seu caráter disciplinador, reproduz heteronormatividade e repertórios de gênero definidos, potencializa que experiências de gênero dissidentes (Butler, 2010; Preciado, 2014) sejam performadas. Não se trata de dizer que estas seriam experiências "circunstanciais", uma vez que, enquanto performatividade, o gênero é sempre contingencial - é algo que se cria, ou se faz (Butler, 2010), cotidianamente, de acordo com as possibilidades, negociações e desejos que se articulam a cada momento. Cabe neste momento deixar nítido que
Performatividade não é performance; a performatividade é o que possibilita, potencializa e limita a performance (Sullivan, 2003; Cameron \& Kulick, 2003; Pennycook, 2007). Entender gênero, sexo, sexualidade, raça, desejo como performativos não é meramente afirmar que eles são uma performance (num sentido estritamente teatral), mas sim que eles são produzidos na/pela/ durante a performance sem uma essência que lhes serve de motivação (Borba, 2014, p.449).

Butler (2010) ainda aponta que só é possível pensar a norma - no caso, a norma heterossexual - a partir do que ela guarda em si de autodestruição; mais do que estar fora da norma, é preciso produzir brechas e fissuras nas normas a partir delas, convocando-as a reorganizarem-se. Para a autora, pensar o gênero tendo a performatividade como eixo é investigar de que maneiras os regimes e sistemas de gênero que constituem "homem" e "mulher" são politicamente acionados e estabelecidos, a que propósitos servem e como são operados. Trata-se, assim, de pensar o gênero como dispositivo histórico e categoria de análise (Scott, 1995), articulando-o a processos políticos e ideológicos.

Ao acionar o conceito de performatividade para pensar a prisão feminina, neste sentido, se

[...] oferece algumas pistas para que possamos acompanhar as dinâmicas das relações de poder e de afeto que são produzidas em contextos de privação de liberdade. Identifica-se, nestas instituições, uma série de hierarquizações e desigualdades pautadas no gênero, que se exprimem tanto na fixação de identidades sexuais e de gênero quanto em movimentos que borram as fronteiras dos gêneros e parecem apontar para possibilidades mais fluidas destas vivências (D’Angelo, 2017, p.110).

Barcinski e Cúnico (2014) apontam que, frente aos processos heteronormativos, disciplinares e homogeneizadores acionados pela prisão, há inúmeros "movimentos de diferenciação" (p. 64) que buscam dar passagens mais potentes aos afetos. Assim, movimentos singulares, outras subjetividades, outros arranjos conjugais, familiares, outros afetos e erotismos são criados, instaurando diversas possibilidades de vivenciar a prisão, os laços familiares, os vínculos 
afetivos e sexuais e, também, o gênero. Quando Enrique narra como se constitui sapatão, nota-se que sua experiência não passa pelos mesmos arranjos, forças e percursos que a experiência de Sandra, também sapatão. Enquanto, para Enrique, ser sapatão fala mais de estratégias de convivência/sobrevivência/criação de laços sexuais e afetivos, para Sandra designa uma categoria a qual entende como favorecedora da produção/efetivação de seus desejos.

O conceito de máscara proposto por Rolnik (2014) pode trazer elementos interessantes para pensar o gênero enquanto performatividade. Elas são

[...] a efetivação das intensidades que se produzem nos encontros, ou seja, como exteriorizações em corpos materiais que exprimem e simulam estas intensidades. A simulação destas intensidades em máscaras configuram "cristalizações existenciais" (Rolnik, 2014, p.33) de caráter provisório, pois pretendem fixar um território inteligível que expresse as intensidades que estão sendo produzidas mas que, por se tratar de formações corporificadas de forças que se movimentam constantemente, modificam-se, dobram-se e desdobram-se de modo que as máscaras têm validade apenas até o momento em que conseguem fazer passar estas intensidades (D'Angelo, 2017, p. 99-100).

Assim, não é o caso de dizer que Sandra, porque não se considerava/apresentava como sapatão antes da prisão, ainda que se relacionasse com homens e mulheres, produz qualquer tipo de ruptura ou mudança no que diz respeito ao que ela é. O que ocorre é que, na prisão, ser sapatão é o que possibilita que seu desejo se efetive, encontre sentido. A máscara sapatão, para ela, é aquela que mais consegue fazer passar as intensidades do desejo. Da mesma forma, para Rubi, sapatão não é uma máscara que permite que passem seus desejos e, por isso, mesmo que sinta que há dificuldade em assumir não ser nem mulher, nem sapatão, vive como lésbica.

Para Enrique, a máscara sapatão toma outros sentidos: é a máscara possível para que ela/ ele $^{8}$ se relacione com mulheres femininas, como deseja, uma vez que a prisão produz hierarquias e disputas entre as categorias utilizadas para identificar aquelas que se relacionam com mulheres femininas, as que performam masculinidades e, ainda, aquelas que se relacionam com estas últimas. Para Enrique, mesmo que acionar esta máscara vá de encontro com outros modos através dos quais ela preferiria narrar a si mesma, ela entende que, naquele contexto, territorializar-se como sapatão é estratégico e necessário.

Ainda que estas máscaras sejam acionadas conforme a possibilidade de passagem do desejo, isso não significa dizer que não há conflitos, violências e desrespeitos por parte da instituição no que tange às experiências de gênero e sexualidade das pessoas presas; há relatos de preconceito e dificuldade no acesso a direitos como a visita íntima, questões básicas de higiene e assistência jurídica. No entanto, foram comuns as falas de que agentes penitenciárias facilitam que casais formados fiquem na mesma cela/cubículo. O que impera como norma é o desejo de que a cadeia fique calma, o que seria possível através da facilitação dos encontros afetivos e sexuais. A ideia de que sexo acalma a cadeia aciona certa forma de entender e dispor o conflito dentro desse espaço demarcado por mecanismos disciplinares e de controle.

As disputas e negociações a respeito destas categorias se dão também entre as presas, que também operam hierarquizações. Vale, aqui, explorar um pouco as diferentes categorias evocadas no campo, o que as diferenciam e que elementos estão presentes em cada performatividade, considerando que, como aponta Rubi, na prisão torna-se importante dizer quem se é, conformando-se a alguma dessas categorias - caso contrário, a não adequação pode significar um sentimento de isolamento. A diferenciação mais frequente é entre lésbica e sapatão: a primeira seria aquela que mantém relações homossexuais, mas que performa uma feminilidade hegemônica - ou que, nas palavras de Rubi, nem tem cara de lésbica, fazendo referência a uma performatividade de gênero lida como feminina. Também são conhecidas pela expressão bolinha-vai-bolinha-vem, pois, nas práticas sexuais, tocam e são tocadas, acionando desta vez não apenas uma expressão de gênero, mas como esta se performa sexualmente no binômio atividade/passividade. É semelhante à entendida, porém esta não quer ser identificada nem como lésbica nem como sapatão, apenas como mulher que gosta de outra mulher, podendo adotar ou não uma performativi-

${ }^{8}$ Assim como várias pessoas nas pesquisas, a personagem Enrique se refere a si mesmo/a no feminino e no masculino em diversas ocasiões. 
dade masculina. Já sapatão seria aquela que pode ou não adotar um nome masculino, mas cuja performatividade de gênero indica traços, atributos, jeitos e/ ou vestimentas lidas tipicamente como masculinas. Sumariante de pederastia ${ }^{9}$ diz respeito a quem é iniciante nas relações entre mulheres - ou outras neste universo prisional.

Há diferenciações entre sapatões, delimitadas especialmente pelas suas trajetórias: há sapatões de rua, que mesmo antes da prisão já haviam tido relações com mulheres; sapatões de berço, que nunca tiveram relações com homens, dizem-se virgens, por nunca terem sido tocados(as) por homens, e cuja performatividade desde muito cedo na trajetória de vida é percebida como masculina. O sapatão sucateiro é aquele que se relaciona com as mulheres/ mulheríssimas/gurias em troca de sucatas $^{10}$, garantindo-lhes proteção. Já o sapatão do alvará apareceu como sendo aquele que deu sorte para suas companheiras que, após namorarem com ele, ganharam a liberdade. Ainda que não haja hierarquizações, os termos qualificadores dos sapatões parecem ser acionados diferencialmente na medida em que se deseja evidenciar determinado aspecto da performatividade/experiência sexual.

Mulheres/mulheríssimas e gurias são aquelas que estabelecem relações com sapatões, relações estas que, geralmente, reproduzem o modelo heteronormativo em que as funções com o cuidado e limpeza ficam a seu encargo, enquanto os sapatões são responsáveis pela proteção e provimento. Aos/às sapatões, ainda, é legitimado que tenham mais de uma companheira e usem de violência, enquanto suas mulheres devem manter-se fiéis a ele/a.

Neste sentido, há distribuições diferenciais de privilégios no cotidiano institucional de acordo com o modo como cada uma/um se nomeia, sendo que os/as sapatões costumam ocupar os lugares de maior prestígio nas relações estabelecidas entre presas(os) e, inclusive, junto à instituição. Ser sapatão numa cadeia feminina dá ibope, dá moral, promove disputas. Um olhar mais atento faz ver que as forças que produzem distinções falam muito mais de movimentos do que fixações, de nuances do que rigidezes, de negociações do que de atestados sobre a verdade do gênero de alguém.
Se ser sapatão é usufruir de um prestígio e poder masculinos que permitem ter mais de uma parceira e lançar mão da violência, ser sapatão também implica em estar no centro de disputas outras que não só podem vir a questionar sua biografia sexual e vida sexual antes da prisão (Padovani, 2015) como, também, questionarão seu lugar de poder e superioridade e, enfim, sua legitimidade. Há, assim, que se manter em constante vigilância e garantir a manutenção do lugar de prestígio que ocupa constantemente, lançando mão de inúmeras estratégias - inclusive nomear-se sapatão sem sentir-se, de fato, sapatão, como é o caso de Enrique.

As experiências de sapatões evidenciam importantes elementos a respeito das vivências de masculinidades, em que a virilidade é um valor frágil, que pode ser perdido a qualquer momento. A vigilância e a cobrança, assim, são muito intensas. Além disso, pessoas designadas mulheres no nascimento performando masculinidades, embora possam exercer certos privilégios, fazem um trânsito não permitido entre os gêneros, entendidos como fixos, exclusivos e excludentes. Especialmente no caso de sapatões, mas não exclusivamente, o antes da prisão traz tensionamentos importantes que se relacionam tanto à passabilidade quanto à legitimidade de ser sapatão. Pela carta de Rubi podemos ver que, ter sido ou não, sapatão antes da entrada na prisão pode ser utilizado como forma de legitimação ou deslegitimação do ser sapatão neste contexto. Por isso ela aponta, com surpresa, o caso do sapatão que saiu da cadeia e, ao ser preso de novo, estava grávido. Ter engravidado fora da cadeia coloca em xeque sua performatividade de sapatão e desestabiliza sua passabilidade. Ainda, Rubi aponta para outro ponto relevante: a passabilidade envolve uma série de complexas tramas, não estando apenas relacionada à performatividade e ao uso/exercício de atributos tipicamente lidos como masculinos. Há uma disputa entre forças que, por um lado, reificam a masculinidade a partir da performatividade masculina mas que, de outro, informam que, mesmo que performando um masculino, não se trata, "de fato", de um homem - nas palavras de Rubi, não adiantaria coçar o pano da calça se, por baixo dele, não há genitais masculinos a serem coçados.

\footnotetext{
${ }^{9}$ Embora, historicamente, seja um termo utilizado para designar relações e práticas sexuais entre um homem e um rapaz mais novo, a pederastia aparece no sistema prisional feminino de maneira recorrente, no que tange ao exercício da sexualidade entre mulheres ou mulheres e outras figuras das unidades femininas.

${ }^{10}$ Sucata é o termo utilizado para designar as sacolas nas quais familiares levam itens para as(os) presas(os) nos dias de visita.
} 
A passabilidade (Duque, 2013) pauta-se na heterossexualidade compulsória e na heteronormatividade (Butler, 2010) para fazer supor que uma pessoa é, obviamente, heterossexual e, portanto, deve ser rápida e visualmente lida como tal. A classificação de lésbica, sapatão, mulheríssima seriam, de alguma forma, atravessadas por estes pressupostos e estereótipos. As transformações nos gestos, modo de andar, de vestir, o corte de cabelo e o uso de top (prendendo os seios) é que narram, visualmente, quem é quem. No entanto, as nuances, intensidades e trajetórias não se deixam ver em um rápido olhar.

Estas designações não se dão apenas pautadas no que há de visível, no corpo, mas também nas práticas e vivências dos desejos. Em um catuque, Enrique nos afirma: sapatões ocupam o lugar do homem. Assim, cabe a eles/as tocar a companheira e dar prazer a ela; em raros casos eles/as podem ser tocados/as durante encontros sexuais, uma vez que isso colocaria em xeque suas performatividades masculinas, pautadas na postura ativa e na negação de atributos físicos femininos a serem estimulados, como os seios.

Já as lésbicas ou bolinha-vai-bolinha-vem, que tocam e são tocadas, ocupam, com mais ou menos passividade, o lugar da mulher. Parece, assim, que a produção de feminilidades e masculinidades nas instituições de privação/restrição de liberdade está intimamente ligada às orientações sexuais e performances de gênero. Poderia-se pensar, neste sentido, em processos de aprisionamentos múltiplos, que se atravessam e são operados concomitantemente, marcados pela prisão em si, mas também pela rigidez e cristalização de experiências sexuais e de gênero, que aprisionam feminilidades e masculinidades em "feminino" e "masculino". Se, para as lésbicas, ser mulher presa diz respeito a ter relações homossexuais sem parecer homem, no caso dos(as) sapatões, é o parecer/ ser homem que é acionado.

É interessante, também, pensar em como as normas que regem o que é ser sapatão e ser lésbica, como por exemplo, a possibilidade ou não de ser tocada/o, podem ser dobradas no tête-à-tête das relações. Ainda que sersapatão não comporte ser tocado/a, Enrique indica: dependendo da relação, deixa-se tocar, desde que a parceira não conte a terceiros. Brechas são possíveis, assim, de modo que a rigidez das normas de gênero, que operam não só as categorias "masculino" e "feminino", mas também sapatão e lésbica, vê-se constantemente atravessada por aquilo que escapa à norma.

\section{Relações afetivo-sexuais e performatividades: entre carências e potências}

As relações afetivo-sexuais que se estabelecem na prisão são atravessadas pelos desejos e disputas que as performatividades de gênero movimentam. Se, por um lado, são narradas a partir de noções como a de carência, por outro também falam de possibilidades múltiplas de viver a sexualidade e o afeto no contexto prisional. Nas seguintes cartas, observamos esses movimentos:

Lá fora, sou casada. Estamos juntas há 6 anos. Aqui dentro, também me relaciono com uma pessoa. Minha mulher já me traiu. Quando eu soube, levei um choque, mas não fiquei chateada porque o amor já não é o mesmo. Ele desgastou pela falta de contato íntimo com ela. Ela não sabe que eu tenho alguém aqui dentro, ainda que já tenha dito que permitiria. Faço isso por carência, se tivesse parlatório não teria necessidade. Eu preciso de alguém pra cuidar de mim. A vida aqui dentro é uma e na rua é outra, eu sei separar isso. Aqui dentro também já me relacionei com duas mulheres ao mesmo tempo. Elas sabiam e queriam que fosse assim. Esse relacionamento triplo foi proposto por elas duas, já que eram muito amigas, irmãs de cadeia, como a gente chama aqui, e durou mais ou menos um mês. Dormíamos as três na mesma cama e fazíamos menáge à trois. Os sapatões ficavam loucos porque queriam transar com elas e ninguém tinha conseguido. Só que em uma época, elas começaram a me pressionar pedindo pra eu escolher uma delas. Escolhi a mais bonita e que também era mais quente, eu gosto de mulheres quentes. (Enrique)

Pra mim é importante dizer logo de cara que eu sou sapatão - faz parte de quem eu sou na cadeia. Fui condenada há quase 6 anos, mas já cumpri 4. Na verdade, eu nem deveria estar aqui, porque não tenho envolvimento nenhum com o tráfico; estava no lugar errado, na hora errada. Pensando bem, é engraçado pensar que minha própria comunidade possa ser "o lugar errado". O que aconteceu foi o seguinte: o pai do meu filho, que não é mais meu companheiro e já não o era na época, é chefe de uma boca. No dia em que fui presa, estava passando por lá, já que tenho ami- 
gos que trabalham nessa boca e moro bem perto dali. Apenas batia um papo com eles quando a polícia chegou e, encontrando uma mochila com $6 \mathrm{~kg}$ de cocaína, prendeu todo mundo. Histórias como a minha são comuns na cadeia; pessoas que, por terem relações de amizade ou amor com alguém envolvido no tráfico, são acusadas de "associação para o tráfico". Eu tenho uma companheira aqui, há 2 anos. A gente pretende continuar nossa relação lá fora. Eu saio antes do que ela, então vou esperar ela sair pra gente construir nossa vida fora daqui. Nossa relação é muito boa, me ajuda a não sofrer tanto com a falta do meu filho. Com ela, dá pra distrair a cabeça e também ter apoio quando fica muito difícil. Apesar da saudade dele, a prisão não é de tudo ruim. Me deu minha companheira, por exemplo. (Sandra)

Foi estranho...beijar outra mulher, tinha peito. Quando encostei no peito dela uma vez, me deu um fora. Mas no início, não encaixei não, demorou uns dois ou três meses para fazer relações. Mulher é coisa estranha para fazer o encaixe. Primeiro, eu achei estranho com mulher, depois eu gostei. Quando fiquei com mulher a primeira vez, estava muito tempo sem ninguém, o que era ruim, é que duas mulheres juntas são tudo em dobro: menstruação, TPM, bijuterias etc., porém, tem mais companheirismo, carinho, a forma de conversar é diferente, cumplicidade. É muito diferente! Pode ser no físico, no visual, na saúde, a mulher vai estar sempre ali. Com homem isso é mais difícil. O que me faz estar com ela é justamente isso, o compartilhar, estar juntas, o cuidar. A pessoa com quem me relacionei fazia o papel do cara, mas ela não é sapatão, é mulher com estilo de cara, bermuda de homem, top. Não tem essa definição. Não deixava eu tocar. Mas eu já toquei, verdade verdadeira, e ela adorou! Numa boa. Era só o ar do cara. Diz que é moral. Quem sou eu? Deixa ela com a moral dela. Mas eu sei, deixa ela fazer alguma coisa...acabo com a marra dela de cara. Mas não falei dela, tô me comportando. Embora tivesse curiosidade para saber como era as relações entre mulheres, nunca tive oportunidade, sendo na prisão minha primeira vez, através de uma amizade despertou um grande amor. (Rubi)

As relações afetivo-sexuais estabelecidas dentro e fora na cadeia falam de processos subjetivos e processos de Estado que entrelaçam desejos, afetos, negociações, acordos, disputas, poderes e violências. Quando Sandra aponta para a circunstância de sua prisão, por exemplo, ela aponta para como as relações familiares, sexuais e de amizade que são tecidas em determinados territórios acionam práticas de Estado que inserem a prisão nas trajetórias de vida de determinados sujeitos. Em seu caso, assim como de outras pessoas nas prisões femininas, manter relações com pessoas envolvidas no comércio varejista de drogas, nas comunidades, faz com sua vida seja atravessada pela prisão: o fato do pai de seu filho e seus amigos serem envolvidos produz condições para que ela seja culpada e vá presa.

A sexualidade está no centro das disputas e tramas cotidianas na prisão, tanto entre as pessoas privadas de liberdade quanto na gestão da unidade por parte da instituição. É ela que permite, por exemplo, determinados trânsitos, a partir de transferências para unir casais em uma mesma cela. A gestão espacial das unidades atravessa as possibilidades de viver relações afetivas e sexuais, facilitando ou dificultando diferentes intensidades de privacidade. Nas celas para duas pessoas, os chamados cubículos, é possível viver maior grau de intimidade de uma vida a dois/a duas. Já nas celas coletivas, os espaços íntimos ficam limitados, mas sempre é possível construir um quieto ${ }^{11}$ e negociar com as/os companheiras/os de cela. As falas sobre o sexo na prisão feminina equilibram-se entre linhas distintas, às vezes sendo ditas abertamente - a partir de uma constatação de que é comum que, neste espaço, as pessoas se relacionem entre si -, às vezes sendo tratada de maneira velada. Assim, o sexo é possibilitado e impedido de ser narrado, ao mesmo tempo, em diferentes intensidades, produzindo formas de controle e gestão dos corpos e das sexualidades que, mais do que impedirem que ela seja exercida, produzem determinadas formas legitimadas de seu exercício.

Neste sentido, as relações afetivo-sexuais, bem como as hierarquizações das categorias que designam performatividades de gênero, são não só, legitimadas

\footnotetext{
${ }^{11}$ Quieto é cama na qual, utilizando fios e lençóis, são feitas espécies de cortina, de modo que é possível estar com outra pessoa com um mínimo de privacidade. Nem sempre as(os) agentes penitenciárias(os) autorizam os quietos, sendo muitos desmanchados durantes revistas às celas. O argumento é pautado na segurança. No entanto, sempre são reconstruídos.
} 
pelo Estado e pela gestão das unidades como, também, acionadas como moedas de troca e negociações no cotidiano institucional. A percepção da sexualidade como moeda de troca lança luz sobre as dificuldades de a sexualidade ser tratada em sua dimensão de direito: vista como moeda de troca, não se trata de garantir o exercício da sexualidade como direito fundamental, mas sim de operacionalizá-la estrategicamente para a gestão dos corpos, conflitos e afetos.

No cárcere, novas formas de sociabilidade e conjugalidade se configuram. As pessoas que se encontram ali criam mecanismos de adaptação e resistência para sobreviver ao isolamento e subjugação e potencializar suas experiências sexuais enquanto estratégias de vida. Talvez seja a isso, também, que Enrique se refere quando afirma que, apesar de não ser sapatão, reivindica esta categoria para falar de si de modo a ser possível se relacionar com as mulheres que o atraem, as que se apresentam como "femininas", já que a união de duas lésbicas não seria tão bem-vista. Ainda, talvez sejam essas estratégias que ele aponta em um catuque, quando afirma que "a vida aqui dentro é uma e na rua é outra" - não porque haja uma separação total entre "dentro" e "fora" da prisão, mas porque o contexto prisional exige diferentes estratégias - ou máscaras, como colocado anteriormente para viver seus desejos.

No centro do atravessamento de forças de controle/estratégias de potencialização está o elemento carência, que aparece com frequência para designar as razões pelas quais as relações afetivo-sexuais são comuns nas prisões femininas - tanto por parte das pessoas presas quanto por parte de diferentes segmentos profissionais. Tanto Enrique quanto Sandra deixam ver as nuances em que a carência aparece como elemento constitutivo de seus relacionamentos com suas companheiras, que têm como uma de suas funções aplacar a solidão produzida pela prisão - seja a solidão produzida a partir do esgarçamento de relações amorosas do lado de fora, como coloca Enrique em uma carta, uma vez que "o amor não é o mesmo" depois da prisão, seja pelo distanciamento do filho, conforme apontado por Sandra.

Estas relações, no entanto, não estão exclusivamente relacionadas àquilo que a prisão produziria de ruptura com o fora, mas também ao que a prisão produz: se, por um lado, Sandra está com sua companheira, pois ela "ajuda a suportar a saudade do filho", por outro, ali na prisão, elas criaram uma relação que pretende estender-se para além da cadeia, continuando lá fora quando as duas saírem. Do mesmo modo, as relações de Enrique com sua esposa fora e com sua companheira dentro, coexistem, certamente causando tensões e negociações, mas também mostrando que diferentes relações podem acontecer e se manter na/apesar da prisão.

Os casais, nas unidades prisionais femininas, aparecem bastante marcados por noções como companheirismo, apoio, ajuda, carência. Para Sandra, sua companheira é importante para ajudar a distrair e suportar a saudade do filho; para Enrique, a companheira cuida dela e supre os desejos sexuais que não podem se concretizar com a esposa que está fora, pela dificuldade de acessar a visita íntima. A carência, portanto, não esgota as relações afetivo-sexuais, mas aponta para importantes elementos dos modos como estas relações se dão e atravessam outras práticas cotidianas na instituição. Barcinski (2012) aponta que o foco no cuidado, na carência e no companheirismo acaba por invisibilizar a dimensão sexual destas relações. Para a autora, esta dinâmica "corrobora a imagem do feminino atrelada ao cuidado e ao empenho na manutenção de relações afetivas" (Barcinski, 2012, p. 438).

No entanto, a carência não é somente acionada em processos de apagamento da dimensão sexual das experiências e relações entre pessoas designadas mulheres no nascimento. Ela é, também, evocada como estratégia de negociação. Compreendendo que a dinâmica institucional reproduz um modelo heteronormativo e padrões de gênero rígidos, chamar a carência para explicar a necessidade de ter seus relacionamentos legitimados pela instituição torna-se importante estratégia, pois é a carência que torna palatável e possível reconhecer estas relações, por exemplo, na hora de juntar, em uma mesma cela, um casal. Afinal, carentes e sem sexo, a cadeia não ficaria calma.

\section{Maternidades, gênero e prisão: sobre ser mãe sendo lésbica e sapatão}

Assim como gênero e sexualidade são atravessados por uma série de forças que complexificam experiências e narrativas, a maternidade na prisão também sofre deslocamentos. Sandra, Rubi e Enrique reivindicam e exercitam diferentes maternidades, como vemos nestas cartas:

Eu tenho filhos, três, como muitas outras mulheres que conheci. Meus filhos mais velhos, como 
acontece com frequência em outras famílias, estão com a minha mãe, mas ela não vai receber a caçula. A neném pode ficar comigo na UMI até os 6 meses, que é o previsto em lei, quando as mães amamentam, e em princípio quem vai cuidar é uma moça que conheci no hospital. Não vejo meus outros filhos há três anos, desde que fui presa: minha mãe não aprova a forma como eu vivia, adulterando cartões de créditos e documentos de identidade - embora aceitasse o dinheiro que vinha dali, e tampouco a forma como engravidei da Maira, em uma visita íntima com um preso, que era meu companheiro na época. Ser homossexual e estar grávida na cadeia é muito difícil, ainda mais com essa exigência de ser uma coisa ou outra. Eu mesma sofri muito preconceito por ser mãe e lésbica. Já é uma vergonha e uma irresponsabilidade cometer crime sendo mãe, o que dirá ainda ter direito a sexo e engravidar na prisão. É isso que ela pensa. Sempre me perguntam se eu não pensava nos meus filhos quando fazia coisa errada. Por muito tempo eu tive vergonha de dizer, mas hoje digo: não. Não pensei nos meus filhos. (Rubi)

Mesmo sendo sapatão, usando cabelo preso e roupas largas, acho que me diferencio um pouco dos outros. Já fui noiva, mas terminei depois que fiquei com uma mulher numa viagem que fiz. Digo que me considero diferente porque, apesar de identificar o meu universo com isso que a sociedade chama de masculino, tenho vontade de ser mãe. Não gosto de me relacionar com homens, mas já até fiquei com um amigo do meu irmão pra tentar engravidar. Graças a Deus, consegui engravidar de primeira. Nossa, foi insuportável! Tive que beber pra suportar aquele momento. Hoje, vejo que valeu a pena. Afinal, o meu sonho de ser mãe era maior que tudo aquilo. Tive duas filhas com ele, mas agora não quero mais filhos. Na verdade, só teria outros filhos se minha atual companheira quisesse - deixaria que ela engravidasse na condição de que o pai da criança fosse o pai das minhas filhas ou um dos meus irmãos. Outro homem não. (Enrique)
Aqui tem umas coisas que eu não entendo. Muito sapatão aqui tem filho, mas tem vergonha de dizer que é mãe. Têm medo de manchar sua reputação de sapatão na cadeia, perder respeito e prestígio. Às vezes, quando os filhos vêm visitar, fingem que são tias ou madrinhas da criança pra que ninguém descubra que é mãe. Eu não entendo. Tenho orgulho de ser homossexual e mãe. Tenho muito orgulho mesmo. Faz um tempo já que não o vejo, mas ele vem me visitar de vez em quando. Já é quase um homem, está com 16 anos. Toda vez que falo dele, meus olhos enchem de lágrimas. É que quando eu vim presa, meu filho tinha 12 anos. Agora, tá com 16... eu perdi muito da vida dele... não vejo a hora de sair daqui pra estar perto dele de verdade, acompanhar tudo de perto. A prisão é muito dura pra quem é mãe, porque a saudade é muito grande. Chega a ser insuportável. Não é como saudade da família, que é ruim, mas você aguenta. Com filho, é diferente. (Sandra)

Falar de maternidade na prisão é falar sobre as pessoas grávidas e também sobre aquelas que já pari$\mathrm{ram}^{12}$. Pessoas que ainda estão amamentando ficam com seus ou suas filhas em unidades separadas, que conta com mais recursos e melhores condições físicas do que as celas comuns. Desta forma, a entrega de filhos e filhas para famílias ou instituições, após o período máximo pelo qual as crianças podem ficar junto de suas mães, implica em voltar para as celas comuns.

O relatório "Dar à luz na sombra" (IPEA, 2015) traça um panorama das condições de exercício da maternidade nas prisões femininas, problematizando os fatores que impedem ou dificultam o exercício da maternidade de mulheres em situação de prisão. Para além das dificuldades e impedimentos ao exercício da maternidade, Rubi, Sandra e Enrique apontam que a maternidade acontece e aciona experiências e estratégias distintas, bem como toma sentidos diversos.

Para Rubi e Sandra, a prisão atravessa suas maternidades a partir da experiência de separação de filhas ou filhos. A distinção que Sandra faz a respeito da saudade da família e da saudade do filho apontam algumas pistas a respeito de como, mais do que parte

\footnotetext{
${ }^{11}$ Em fevereiro de 2018, a 2a turma do Supremo Tribunal Federal (STF) concedeu um habeas corpus coletivo a mulheres que, em cumprimento de prisão preventiva, estivessem grávidas ou fossem mães de crianças de até 12 anos de idade. A determinação foi em favor da substituição, em todo território nacional, da prisão preventiva pela domiciliar. No que tange a decisão, tensões que se colocam no atravessamento entre gravidez, maternidade e cárcere puderam ser reconfiguradas.
} 
da família enquanto algo genérico, filhos e filhas ocupam um lugar privilegiado na produção de afetos e saudades. A construção da ideia de uma maternidade sacralizada e, ao mesmo tempo, alvo de julgamentos morais, aparece como elemento importante para pensar a prisão feminina desde a construção destas instituições, que no Brasil se deu na década de 40 (Lima, 1983). Desse modo, há toda uma construção social e política em torno da maternidade que tem, como um de seus efeitos, expectativas padronizadas que colocam filhos e filhas como prioridade. Quando Rubi conta que, por muito tempo, teve vergonha de dizer que não pensou em seus filhos quando fazia coisa errada, ela aponta para esta dinâmica entre as expectativas de uma maternidade padronizada e sacralizada e as experiências reais de uma maternidade inserida em contextos de vida e trajetórias específicas.

Rubi aponta que, por ser lésbica, sofreu preconceito quando engravidou. Os julgamentos eram oriundos do fato de que, como lésbica, Rubi não havia decidido se era mulher ou sapatão. No entanto, sendo lésbica, a dificuldade de conformá-la nas categorias mulher ou sapatão implica também em uma dificuldade de julgar o fato de ela ter engravidado. Ainda, o fato de esta gravidez ter sido fruto de uma visita íntima com um homem, coloca outros tensionamentos, na medida em que borra ainda mais o lugar que Rubi ocupa, este lugar pouco delimitado de alguém que, mesmo lésbica, mesmo tendo relacionamentos com mulheres na prisão, mantém relações com homens.

Sandra recoloca o que foi pontuado por Rubi a respeito da deslegitimação dos sapatões que são mães, o que implica na vergonha de ter filhos ou filhas e a consequente escolha por esconder esta parte de suas vidas. Diferentemente de sapatões que escondem suas e seus filhos, passando-se por madrinhas ou tias, Sandra tem orgulho de ser mãe e homossexual, não vê sua performatividade de gênero ser colocada em xeque. Da mesma forma, Enrique também faz coexistir sua performatividade, seu desejo/suas relações afetivo-sexuais e o sonho de ser mãe, tendo inclusive tomado medidas drásticas para tanto.

\section{Considerações finais}

A partir das três pesquisas que fizeram parte do campo de análise deste texto, pudemos observar que, mesmo que, num primeiro momento, os lugares desempenhados nas relações sexuais, eróticas, afetivas e de poder estejam muito demarcados nos dis- cursos, tais como o sapatão, a lésbica, a guria, existe fluidez possível desses contornos. O acionamento de determinadas categorias para narrar a si, suas relações e suas performatividades de gênero é atravessado por uma série de disputas, negociações, afetos e desejos e é tensionado por estratégias de controle e de potencialização das experiências, estratégias estas que não operam de maneira única nem excludente, masa partir de uma trama complexa de poderes.

As performatividades de gênero podem ser entendidas a partir da ideia de máscara, na medida em que apontam para diferentes modos e estratégias de colocar-se no mundo e dar sentido às experiências. Desta forma, falar de performatividades de gênero no contexto das prisões femininas é falar sobre uma multiplicidade de performatividades e relações, e neste sentido falam do caráter processual e de transformação que produz gêneros, sexualidades e afetos.

Nota-se, ainda, que cada unidade prisional produz diferentes negociações e arranjos entre as pessoas, tanto no que diz respeito aos casais ali formados quanto destes com as e os agentes penitenciários e com a instituição de forma geral. O tamanho das celas e a quantidade de pessoas nelas, por exemplo, circunscrevem diferentes formas com que os espaços são gestionados e as subjetividades controladas, o que por sua vez tem efeitos na flexibilização ou rigidez dos discursos e práticas de categorização sexual e de gênero. Também, o fato de as unidades serem destinadas a cumprimento de regimes fechados ou semiabertos tem efeitos na intensidade das relações das pessoas ali dentro, em grande medida devido à abertura ou fechamento das porosidades dos muros da prisão, o que tem atravessamentos nas performatividades de gênero.

Nesse sentido, os mecanismos disciplinares das unidades nas suas porosidades mais ou menos abertas com o "fora" vão produzindo repertórios de gênero diversos, afetando a relação entre a expressão de si e a forma de se relacionar. A prisão é um território que movimenta nossa forma de olhar para o gênero e suas performatividades e evidencia o caráter de experimentação do gênero e da sexualidade. Essas experiências, por sua vez, sugerem a relevância e centralidade do gênero e da sexualidade para a organização e gestão de vidas e instituições. Ao mesmo tempo, essas experimentações, por vezes distantes das reivindicações identitárias dos movimentos sociais e da academia, nos convidam a pensar na importância de 
pluralizar as estratégias de garantia da dignidade das pessoas, bem como de produção de relações igualitárias e justas.

Parece importante pensar na relevância de estudos no campo da prisão e do gênero para a Psicologia que busquem explorar a pluralidade e a complexidade dos processos de subjetivação em instituições prisionais e que considerem as forças institucionais, políticas, culturais e históricas que se instauram nas singularidades das vivências de restrição e privação de liberdade.

\section{Referências}

Barcinski, M. (2012). Expressões da homossexualidade feminina no encarceramento: O significado de se "transformar em homem” na prisão. Psico-USF, 17(3), 437-446. https://doi.org/10.1590/S1413-82712012000300010

Barcinski, M., \& Cúnico, S. D. (2014). Os efeitos (in)visibilizadores do cárcere: As contradições do sistema prisional. Revista Psicologia, 28(2), 63-70.

Batista, N. (2010). Introdução. Sessão de Abertura. In: P. V. Abramovay, \& V. M. Batista (Orgs.). Depois do grande encarceramento (Seminário). Rio de Janeiro, RJ: Revan.

Bicalho, P., Rossotti, B., \& Reishoffer, J. (2016). A pesquisa em instituições de preservação da ordem. Rev. Polis $e$ Psique, 6(1), 85-97. https:// doi.org/10.22456/2238-152X.61384

Borba, R. (2014). A linguagem importa? Sobre performance, performatividade e peregrinações conceituais. Cadernos Pagu, (43), 441-474. http://dx.doi.org/10.1590/0104-8333201400430441

Butler, J. (2010). Problemas de gênero: Feminismo e subversão da identidade (R. Aguiar, Trad., $3^{\mathrm{a}}$ ed.). Rio de Janeiro, RJ: Civilização Brasileira.

Coimbra, C. M. B., \& Nascimento, M. L. (2008). Análise de implicações: desafiando nossas práticas de saber/poder. In: A. R. R. Geisler, A. L. Abrahão, \& C. M. B. Coimbra (Orgs.). Subjetividades, violência e direitos humanos: Produzindo novos dispositivos em saúde (pp. 143-153). Niterói, RJ: EdUFF.

Departamento Penitenciário Nacional (BR). (2018). Levantamento Nacional de Informações Penitenciárias: InfoPen Mulheres ( $2^{a}$ ed.). Brasília, DF: Departamento Penitenciário Nacional. Recuperado de http://depen.gov.br/ DEPEN/depen/sisdepen/infopen-mulheres/infopenmulheres_arte_07-03-18.pdf

D’Angelo, L. (2017) Entre "sujeita-mulher" e "mulher de bandido": Produções de feminilidades em contexto de privação de liberdade (dissertação de mestrado). Pós-graduação em Psicologia Social, Universidade do Estado do Rio de Janeiro, Rio de Janeiro, RJ, Brasil.

De Garay Hernández, J. (2018). O adolescente dobrado: Cartografia feminista de uma unidade masculina do Sistema Socioeducativo do Rio de Janeiro (tese de doutorado). Pós-graduação em Psicologia Social, Universidade do Estado do Rio de Janeiro, Rio de Janeir, RJ, Brasil.

Duque, T. (2013). Gêneros incríveis: Identificação, diferenciação e reconhecimento no ato de passar por (tese de doutorado). Programa de Pós-Graduação em Ciências Sociais, Universidade Estadual de Campinas, Campinas, SP, Brasil.

Instituto de Pesquisa Econômica Aplicada - IPEA. (2015). Dar à luz na sombra: Condições atuais e possibilidades futuras para o exercício da maternidade por mulheres em situação de prisão. Brasília, DF: Ministério da Justiça, IPEA.

Kastrup, V., \& Passos, E. (2015). Cartografar é traçar um plano comum. In: E. Passos, V. Kastrup, \& L. Escóssia, (Orgs.), Pistas do método da cartografia: Pesquisa-intervenção e produção de subjetividade. Porto Alegre, RS: Sulina.

Leite, M. (2014). Cartografar (n)a prisão. Estudos e Pesquisas em Psicologia, 14(3), 795-813.

Lima, E. M. (1983). Origens da prisão feminina: O período das freiras (1942-1955). Rio de Janeiro, RJ: OAB/RJ.

Padovani, N. (2015). Sobre casos e casamentos: Afetos e "amores" através de penitenciárias femininas em São Paulo e Barcelona (Tese de Doutorado). Instituto de Filosofia e Ciências Humanas, Universidade Estadual de Campinas, Campinas, SP, Brasil.

Padovani, N. (2017). Luana Barbosa dos Reis, presente!: Entrelaçamentos entre dispositivos de gênero e feminismos ocidentais humanitários diante das violências de estado. In: F. Mallart, \& R. Godoi (Orgs.), BR111 a rota das prisões brasileiras (v. 1, pp. 99-115). São Paulo, SP: Veneta. 
Psicologia: Ciência e Profissão 2018 v. 38 (núm. esp.2), 44-59.

Preciado, B. (2014). Manifesto contrassexual (M. P. G. Ribeiro, Trad.). São Paulo: n-1 edições.

Resolução SEAP no 558, de 29 de maio de 2015. Diretrizes e normativas para o tratamento da população LGBT no sistema penitenciário do Estado do Rio de Janeiro. Recuperado de http://www.rj.gov.br/web/seap/exibeconteudo?article-id=2787526

Rich, A. (2010). Heterossexualidade compulsória e existência lésbica. Bagoas - Estudos gays: gêneros e sexualidades, 4(5), 17-44.

Rolnik, S. (1993). Pensamento, corpo e devir: Uma perspectiva ético/estético/política no trabalho acadêmico. Cadernos de Subjetividade, 1(2), 241-251.

Rolnik, S. (2014). Cartografia sentimental. Transformações contemporâneas do desejo (2 ed.). Porto Alegre, RS: Sulina.

Rubin, G. (1975). The traffic in women: Notes on the 'political economy' of sex. In: R. R. Reiter (Ed.), Toward an anthropology of women (SOS Corpo e Cidadania, Trad., pp. 157 - 210). New York, NY: Monthly Review Press.

Salles, M. (2014). Caosmofagia: A arte dos encontros (1 $1^{\text {a }}$ ed.). Rio de Janeiro, RJ: Garamond.

Scott, J. (1995). Gênero: Uma categoria útil de análise histórica. Educação \& Realidade, 20(2), 71-99.

Tedesco, S. H., Sade, C., \& Caliman, L. V. (2013). A entrevista na pesquisa cartográfica: A experiência do dizer. Fractal, Revista de Psicologia, 25(2), 299-322. https://doi.org/10.1590/S1984-02922013000200006

Luisa Bertrami D’Angelo

Doutoranda em Psicologia Social na Universidade do Estado do Rio de Janeiro (UERJ), Rio de Janeiro - RJ. Brasil

E-mail: luisabertrami@gmail.com

(iD) https://orcid.org/0000-0001-5724-3511

\section{Vanessa Pereira de Lima}

Doutoranda em Psicologia Social na Universidade do Estado do Rio de Janeiro (UERJ), Rio de Janeiro - RJ. Brasil.

E-mail: vanny.psico@gmail.com

(iD) https://orcid.org/0000-0002-0300-431X

Vanessa de Andrade da Costa

Graduanda em bacharel em Letras-Português/Literaturas na Universidade Federal do Rio de Janeiro (UFRJ), Rio de Janeiro - RJ. Brasil.

E-mail: anddradevanessacosta@outlook.com

(iD) https://orcid.org/0000-0002-7869-9910

\section{Jimena de Garay Hernández}

Pesquisadora na Universidade do Estado do Rio de Janeiro (UERJ), Rio de Janeiro - RJ. Brasil.

E-mail: jime_degaray@hotmail.com

(iD) https://orcid.org/0000-0002-0564-1056

\section{Bárbara Silva da Rocha}

Doutoranda em Psicologia Social na Universidade do Estado do Rio de Janeiro (UERJ), Rio de Janeiro - RJ. Brasil.

E-mail:barbararocha02@hotmail.com

(iD https://orcid.org/0000-0002-5669-1029

\section{Gabriela Salomão Alves Pinho}

Professora de Psicologia do Instituto Federal do Rio de Janeiro, Rio de Janeiro - RJ. Brasil.

E-mail: gabriela.pinho@ifrj.edu.br

(iD) https://orcid.org/0000-0003-1413-3309 


\section{Anna Paula Uziel}

Professora Associada do Instituto de Psicologia da Universidade do Estado do Rio de Janeiro (UERJ), Rio de Janeiro

- RJ. Brasil.

E-mail: uzielap@gmail.com

Endereço para envio de correspondência:

Rua São Francisco Xavier, 524, sala 10019, bloco “f”, Maracanã - Rio de Janeiro. CEP 20550-013

Recebido 17/08/2018

Aprovado 23/08/2018

Received $08 / 17 / 2018$

Approved 08/23/2018

Recibido 17/08/2018

Aceptado 23/08/2018

Como citar: D’Angelo L. B., Lima, V. P., Costa, V. A., Hernández, J. G., Rocha, B. S., Pinho, G. S. A., \& Uziel, A. P. (2018). Performatividades de gênero em unidades prisionais femininas do Rio de Janeiro. Psicologia: Ciência e Profissão, 38(n.spe.2), 44-59. https://doi.org/10.1590/1982-3703000212199

How to cite: D’Angelo L. B., Lima, V. P., Costa, V. A., Hernández, J. G., Rocha, B. S., Pinho, G. S. A., \& Uziel, A. P. (2018). Gender performativities in female prison units in Rio de Janeiro. Psicologia: Ciência e Profissão, 38(n.spe.2), 44-59. https://doi.org/10.1590/1982-3703000212199

Cómo citar: D’Angelo L. B., Lima, V. P., Costa, V. A., Hernández, J. G., Rocha, B. S., Pinho, G. S. A., \& Uziel, A. P. (2018). Performatividades de Género en Unidades Penitenciarias femeninas de Río de Janeiro. Psicologia: Ciência e Profissão, 38(n.spe.2), 44-59. https:// doi.org/10.1590/1982-3703000212199 